December 2017

\title{
[For the system, alternate title: If It Sort of Looks Like a Duck: Reflecting on Bad Photographs and Chains of Custody]
}

Jodi Kearns

University of Akron, jkearns@uakron.edu

Brian C. O'Connor

Visual Thinking Laboratory, College of Information, University of North Texas, brian.oconnor@unt.edu

Please take a moment to share how this work helps you through this survey. Your feedback will be important as we plan further development of our repository.

Follow this and additional works at: https://ideaexchange.uakron.edu/docam

Part of the Digital Humanities Commons, Fine Arts Commons, Photography Commons, Scholarly Communication Commons, and the Visual Studies Commons

\section{Recommended Citation}

Kearns, Jodi and O'Connor, Brian C. (2017) "[For the system, alternate title: If It Sort of Looks Like a Duck:

Reflecting on Bad Photographs and Chains of Custody]," Proceedings from the Document Academy: Vol. 4 : Iss. 2 , Article 9.

DOI: https://doi.org/10.35492/docam/4/2/9

Available at: https://ideaexchange.uakron.edu/docam/vol4/iss2/9

This Conference Proceeding is brought to you for free and open access by University of Akron Press Managed at IdeaExchange@UAkron, the institutional repository of The University of Akron in Akron, Ohio, USA. It has been accepted for inclusion in Proceedings from the Document Academy by an authorized administrator of

IdeaExchange@UAkron.For more information, please contact mjon@uakron.edu, uapress@uakron.edu. 


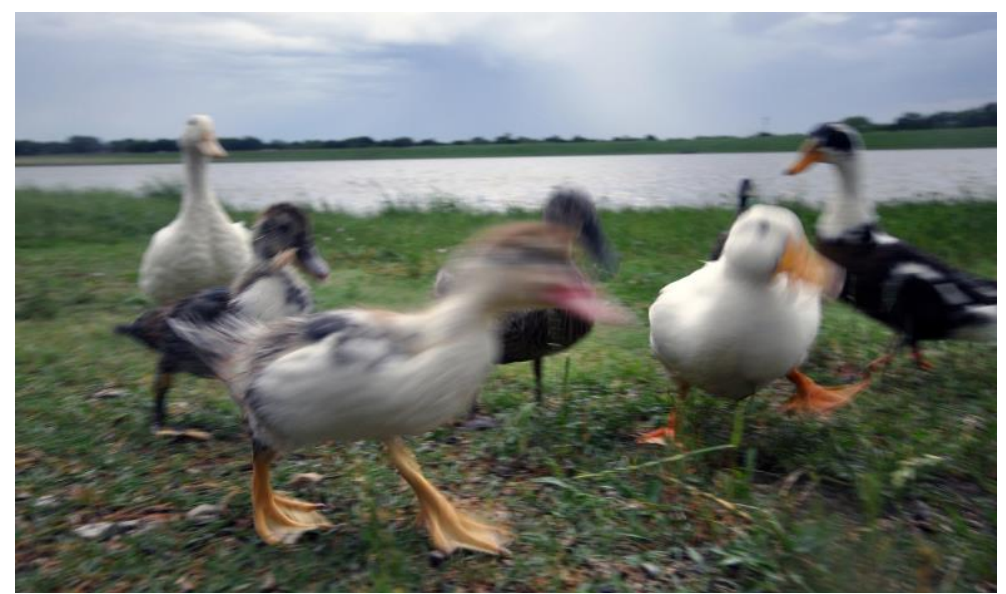

Image1: Article Title, [For the system, alternate title: If It Sort of Looks Like a Duck:

The photograph above is our title for this piece. "If It Looks like a *uck" is the title for our 2016 proceedings piece on "bad words," so we thought it appropriate to use a less than "good" photograph of a duck to echo the use of ' $*$ ' to indicate badness of words, using a common device of polity and censorship.

In 1922, Eastman Kodak's book How to Make Good Pictures: A Book for the Amateur Photographer was already in its twelfth printing; it decried pictures fuzzy from movement, under-exposed, and displaying a horizon that is not horizontal. A picture such as ours, having such characteristics might be supposed to be a "bad" picture.

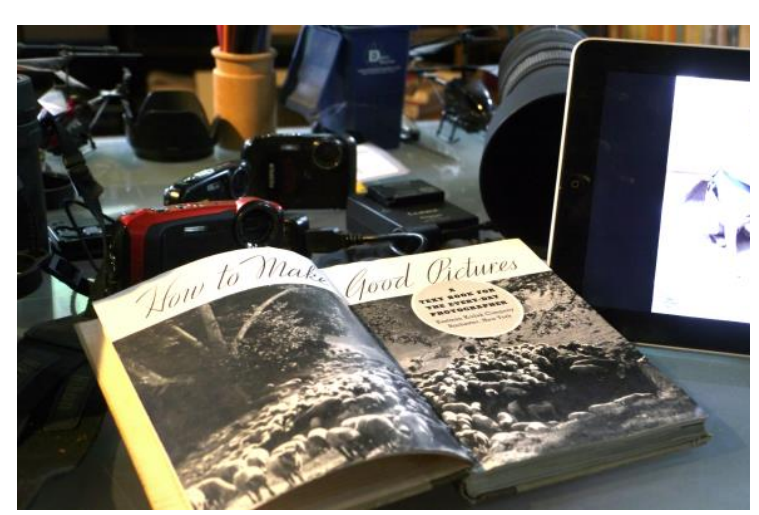

Image2: Photograph of Eastman Kodak's book How to Make Good Pictures: A Book for the Amateur Photographer

The photograph is also used as the title to pique the reader's interest in the uses of photographs; just why would a photograph not make an appropriate title? What would one do about access and retrieval if there were no alternate title? Why are words the dominant mode of communication? What 
can we imagine in a world where photographs are nearly as simple to produce and publish as word documents?

Here we use "bad pictures" to clarify and elucidate the place of photographs in our general model of message making and message use. We assume that photographs are simply messages and are not inherently good or bad; we assume that the "bad" is a description of the relationship of the maker or user with a photograph. We have been thinking together about photographs and words for two decades now. We have done so, in part, because photographs present the possibility of changing the ways we remember, the tools with which we think, and perhaps even the structure of culture in fundamental ways (Flusser, 2000). Echoing Oliver Wendell Holmes, we see photographs as "mirrors with memory: the first means of recording photon data and making it available across time and space." For much of the time we have been thinking about photographs, we have used the expression that on the whole "words (nouns) are general, while photographs are specific." This is a useful but not particularly robust or detailed model. For some time we have used a model of communication proposed by Robert Hayes (1993), that asserts the partners in a communication are like partners in a dance - each must know or assume some coding and decoding abilities of the other (Kearns and O'Connor, 2004). Each codes and decodes through a template of understanding. We are seeking to explicate what such a template of understanding might look like in a dance of photographic communication. In order to flesh out just what might be in those models of internal states we have done some experimenting and thinking about words and photographs, which we share here with you.

Here we articulate elements of templates of understanding for making and using photographs, and we propose "chain of custody" as a model for the specificity of photographs. One method that we have found useful for provoking our thinking is simply to ask people conversational questions. For the DOCAM 2016 gathering we put out a request for folks to tell us a bad word or words and what acceptable or "not bad" word could be used instead. For DOCAM 2017 we asked in the same informal way what seemed to be a similar question: send us a bad picture or tell us what would constitute a bad picture. The responses were provocative.

There were no analogs to "vulgarity" or "inappropriateness;" no full frontal nudity with black bars or digital cloudiness over "offensive" portions of the image; no images of religious figures or implements alone or in some out of the ordinary setting. Rather, bad photographs were portraits that did not 
match well with the sender's self image - driver license picture, high school yearbook picture, unflattering swimsuit picture - or images that did not meet some technical standard - too dark, out of focus, not aimed at anything interesting.

We have made a simple distinction between words and photographs: the former are, on the whole, general; while the latter are, on the whole, specific. That is, words - here, specifically nouns - name classes of entities which share some attribute; photographs record and present photon data of a particular event - an object at a specific time and place. This results in differences between the coding and decoding of messages made from images and those made from words. Ethan O'Connor (2008) suggests using the term "chain of custody," ordinarily used in court cases and medical systems, as an analogy for the differences. The photons viewed in the photograph have a direct and, potentially, traceable connection to an actual physical entity; this is generally not the case for a noun. We agree with Holmes that the indexicality, the very specificity of photographs, renders them fundamentally different from words.

We see something when photons interact with an object to generate a stream of photons that our eyes transect. Human eyes only detect a small portion of the electromagnetic spectrum, what we term visible light. Such detection enables knowing some things about objects at a distance. 


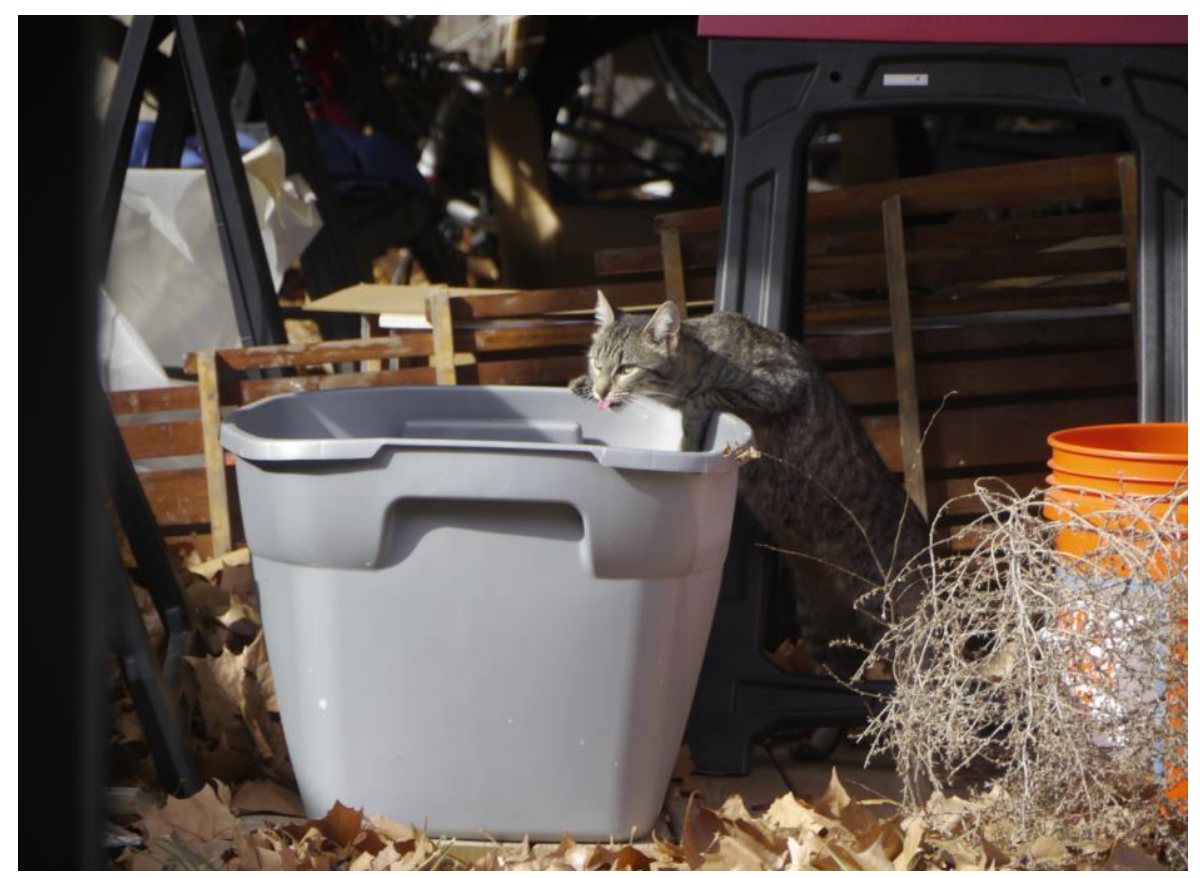

Image3: Photograph of a cat drinking from a bucket full of rainwater in a messy boat shop

We might, for example, see a cat drinking from a bucket full of rainwater in a messy boat shop. A digital camera enables close, precise analysis of photon data. In this particular case there is a grid of 15,925,248 picture elements (pixels.) For each one of the nearly 16 million pixels we can give a precise account of the color components; so here, a point on the tongue of the cat: 


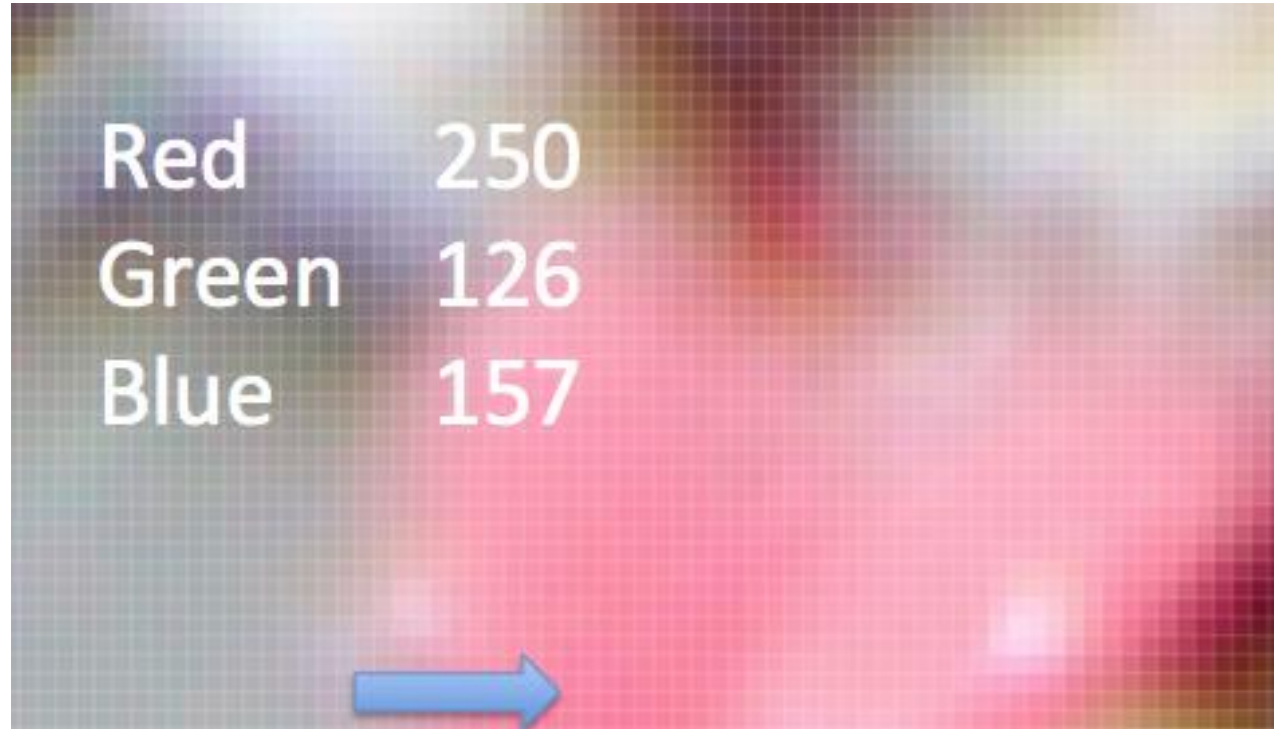

Image4: Representation of color detection on digital image

Most digital imaging systems these days use a system of red detection, green detection, and blue detection, mimicking human color perception in which one cluster of detectors (cells in the retina) responds to red wavelengths of the electromagnetic spectrum; another cluster responds to green; and yet another to blue. Generally the scale by which the amount of each frequency is measured has 256 steps - 0 to 255 . Thus, the pixel above that represents data from the tip of the cat's tongue, displays a lot of red (250 on a scale in which 255 is the deepest red), but this is mixed with some green and some blue (each of these at roughly halfway up the scale.)

We can say that photons have certain traits that can be recorded: direction of travel, location wavelength, intensity, and variation in time and space. We can then say that photography is a means of recording photon data at some particular time; that photography provides a means of recovering vector states of the past; that photography provides a means of comparing some vector space 1 to some vector space 2 ; and that photography thus provides possibly provides more direct mapping to previous states than might words.

We have mechanisms and procedures for assuring and maintaining the accuracy of that photon data across time; thus, we have a form of 'chain of custody' - a direct link to a former vector state, a direct link to what a specific 
entity 'looked like' at some time in the past. Whether we mean a Julia Margaret Cameron portrait of Herschel or selfie of mere seconds ago is irrelevant. We might map a chain of custody as:

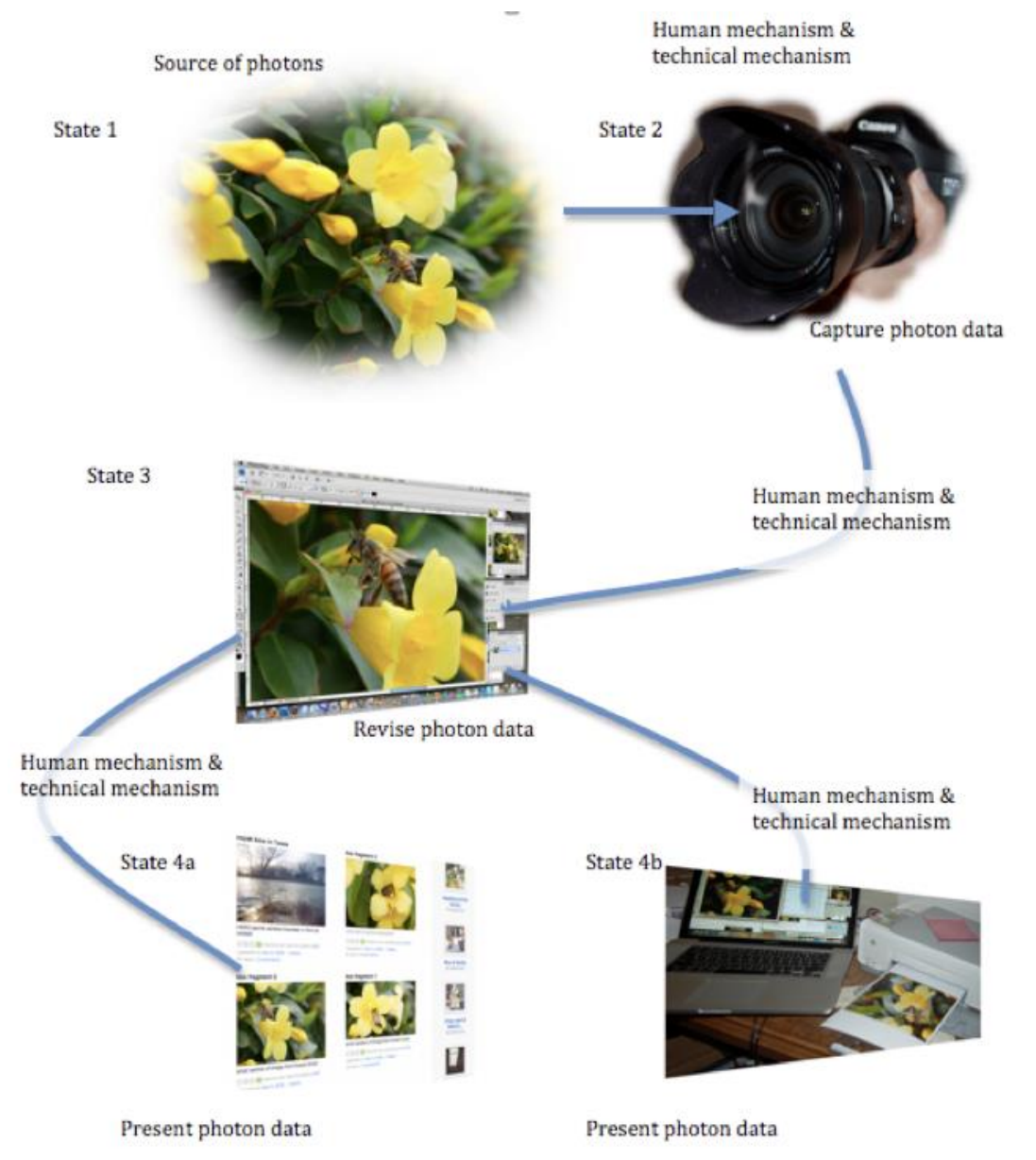

Image5: Chain of custody in photon data across time

We can thus say with Holmes: Our own eyes lose the images pictured on them. Parents sometimes forget the faces of their own children in a separation of a year or two. But the unfading artificial retina which has looked upon them retains their impress, and a fresh sunbeam lays this on the living nerve as if it were radiated from the breathing shape. 
Given any particular set of photographic instruments, we can present a record of photon data to any sighted person and that person will perceive the data presentation largely the same way; there is no need for translation of the message. Yet, it is quite evident that personal and cultural internal models impact the construction of photographic methods as well as their subsequent viewing. What are the aspects of the model that privilege some photons over others. There are lists of words that are not to be said under certain circumstances; how would we model the photographic analogs?

In our earlier work on understanding videos we adopted Hayes' model of communication as a dance meaning arising from the interactions of the two partners. We then devised the notion of templates of understanding (O'Connor, Kearns, and Anderson, 2008) to describe the sets of attributes each party brings to the dance-the communication episode.

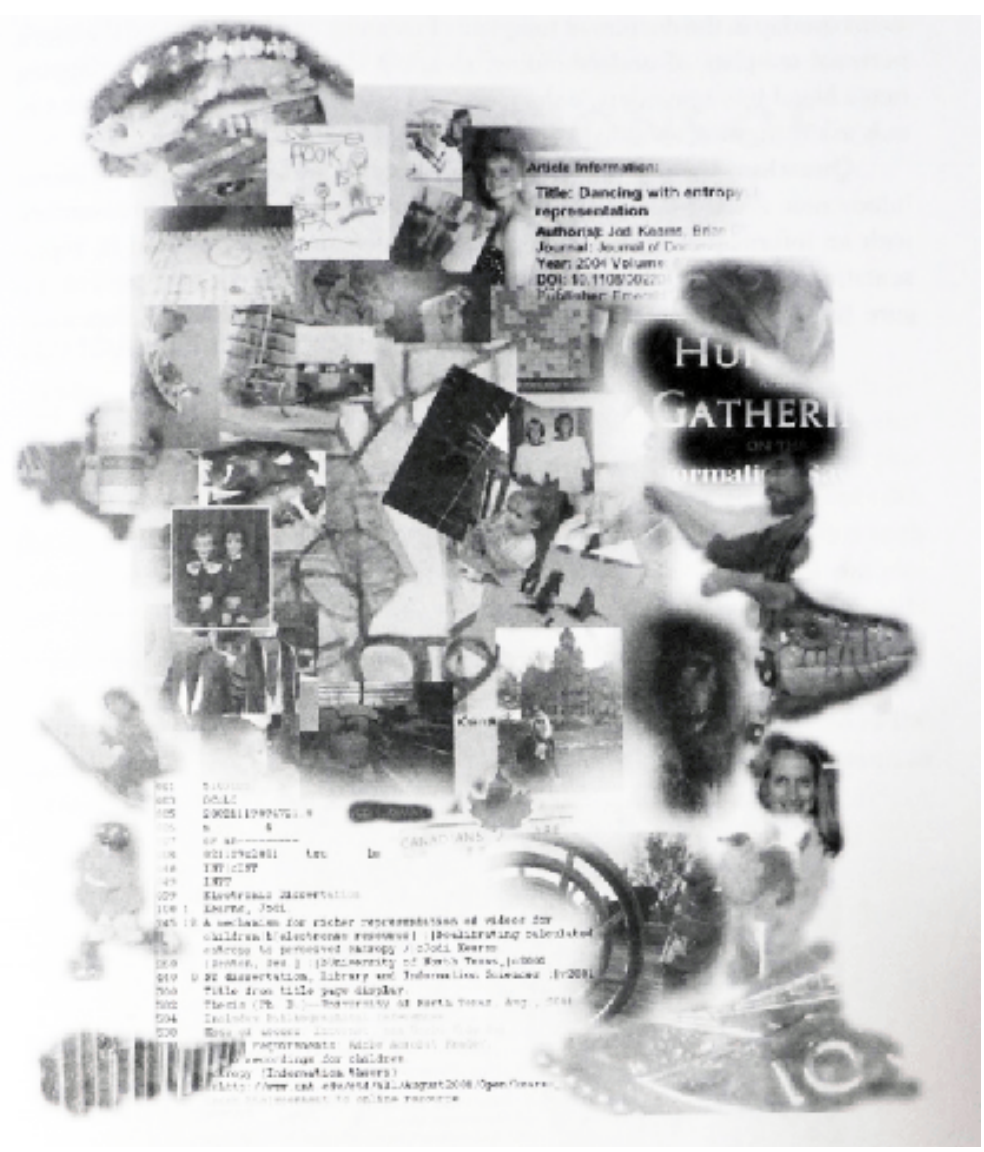

Image6: Representation of Templates of Meaning from Doing Things With Information (O'Connor, Kearns, Anderson, 2008) 
This had roots in the notion of "common ground," which Anderson remodeled in a behaviorist sense as the "ontological commons." This yielded a means of modeling complex sets of relations. Here we are proposing some often significant elements of photo communication templates of understanding, and so, significant relations within the ontological commons.

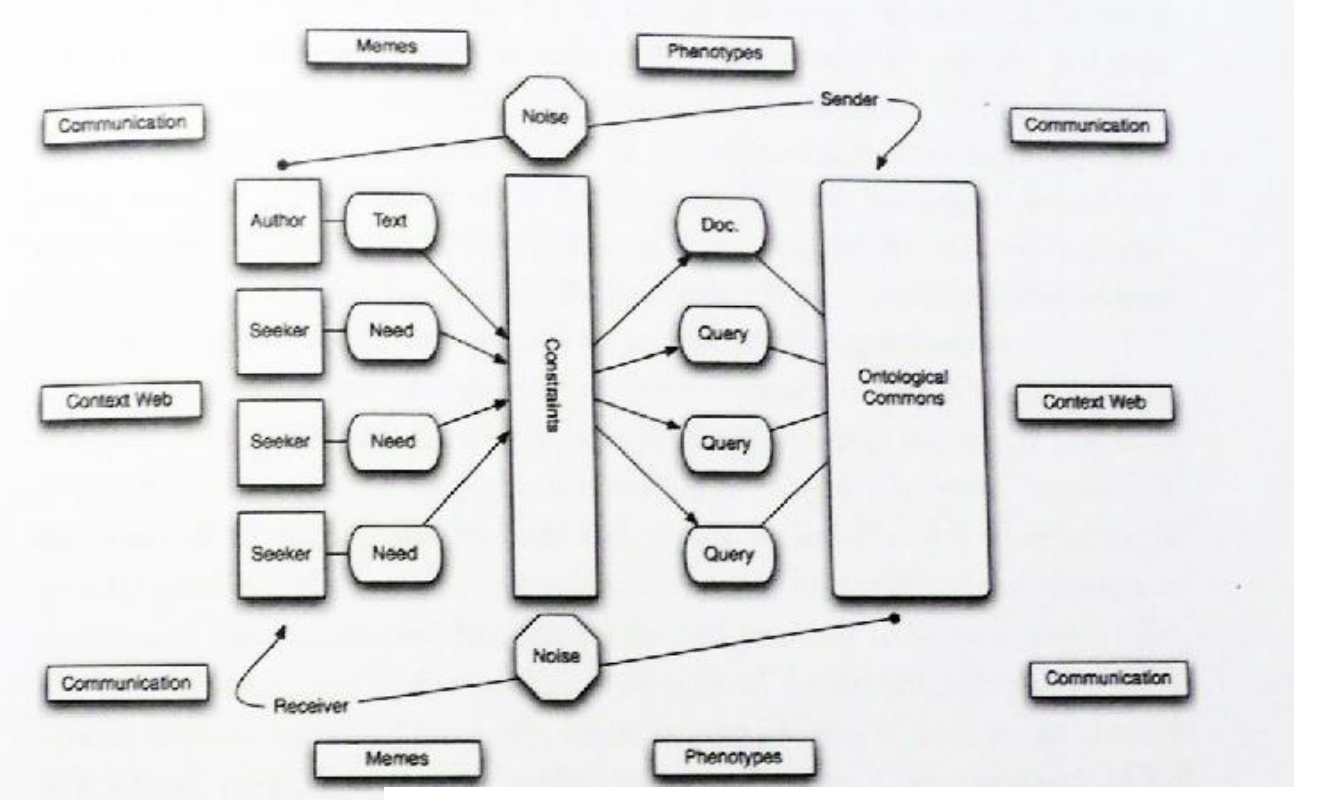

Image7: "Ontological commons" from Doing Things With Information (O'Connor, Kearns, Anderson, 2008)

Privileging Photons

We gathered photographs from sources that had some claim to presenting sanctioned photographs and considered in what ways photons were privileged - or not. At first we expected two sorts of privilege: mechanical (the resolving capabilities of the lens, for example) and conceptual: (frontal nudity or not, for example.) A third category emerged: crossovers (for want of a better term) in which mechanical difficulties (or what would have been called such at a time other than that of the publication) or in which cultural norms are challenged by implications in the photograph.

For examples and in hopes of stimulating more conversation we present a few of the examples of the images and a few of our thoughts on the mechanical and conceptual constraints on pixels presented. 


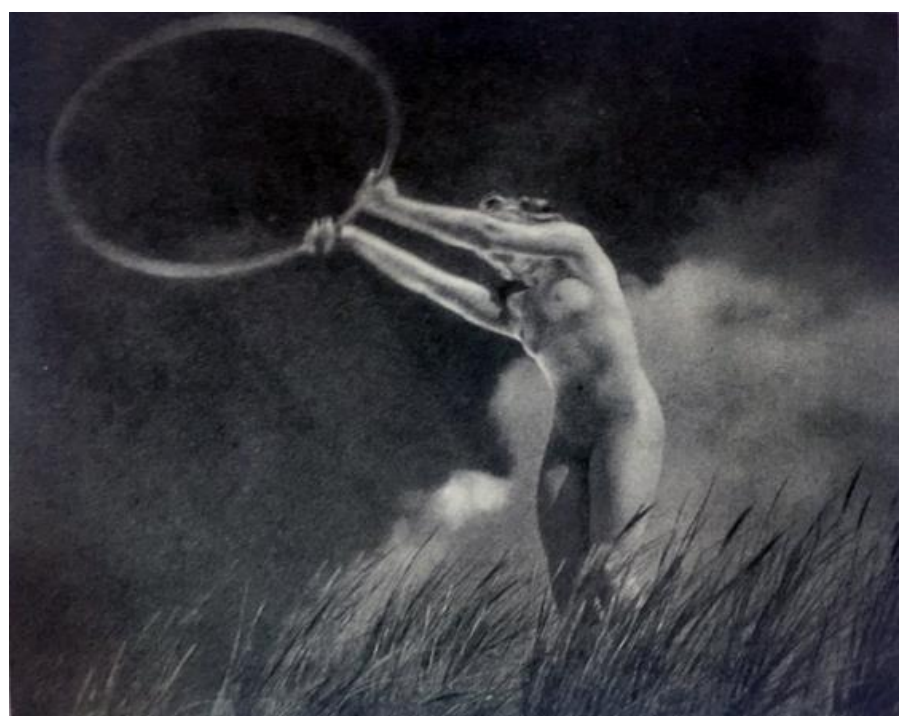

Image8: Leni Riefenstahl photograph
Leni Riefenstahl documented the 1936 Olympics in a film media historian Kevin Bownlow, his introduction to Riefenstahl's memoir Olympia, calls it "too imaginative and poetic to be called a documentary." One still image from the production here presents a frontal female nude. The image is black and white and a bit "grainy" by modern

standards, while the subject and composition meet all classic standards.

In 2012 ESPN photographed former Olympian Ronda Rousey in color with studio lighting and high resolution digital capture for their series Body Issues. The photon data capture system is more sophisticated than the system used by Riefenstahl and her team, but the photons privileged to be seen by the general viewership are restricted to those above her hips, though those photon data were seen by the imaging team, the graphic artists, and production crew. The differential privileging of viewing the photon data is indicated by the image of the photographer

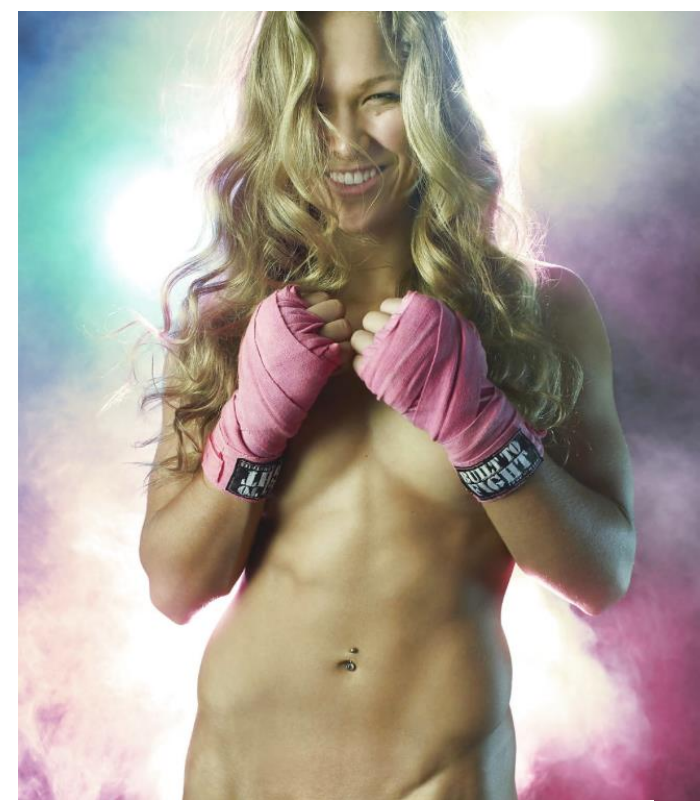

Image9: 2012ESPN photograph of martial artist imaging the female fencer below. 
We see a similar contrast of recording mechanisms and privileged photons from the subjects in the Riefenstahl discus thrower image (paired with the classical Myron discus thrower statue) and the similar soccer player image made by ESPN. Riefenstahl had primitive cameras and different constraints on what could be shown.

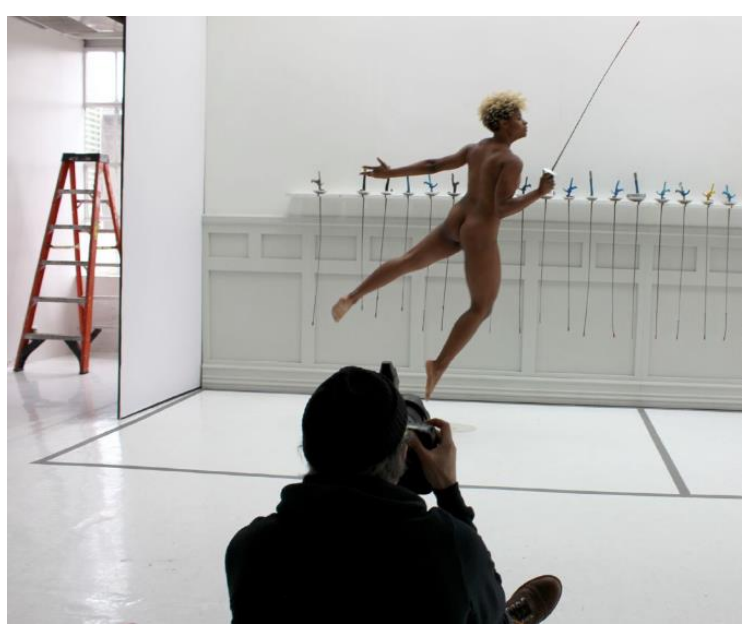

Image10: 2012 ESPN photograph of fencer

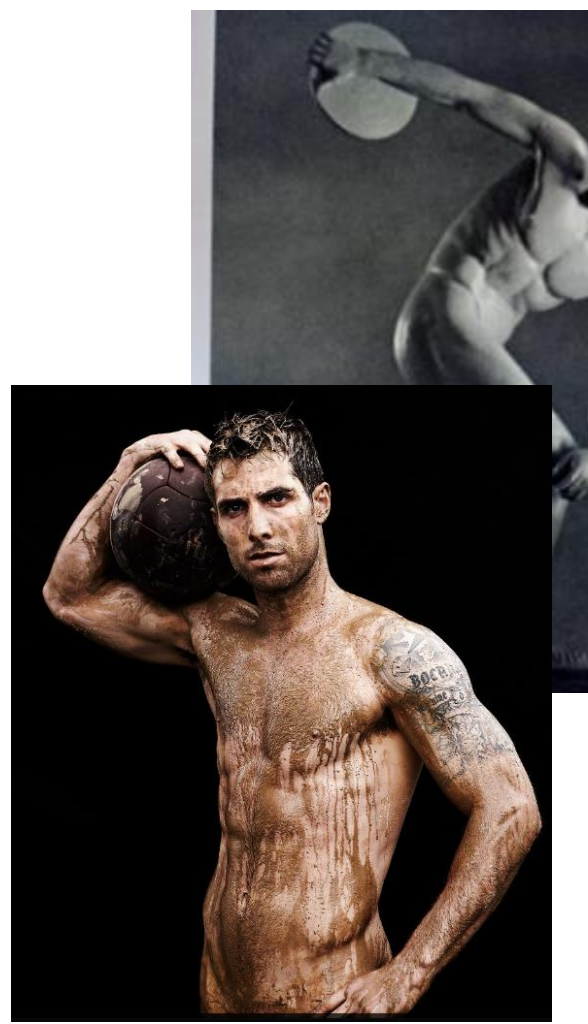

Images11,12: 2012 ESPN photograph of soccer player; 1936 Riefenstahl photograph of discus thrower

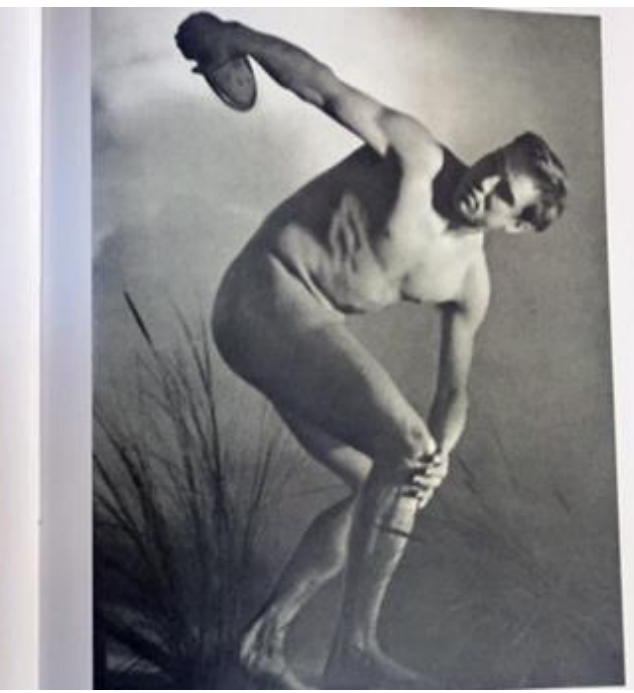

So we have significant differences in the technology of photon data capture and differences in the cultural constraints on which photon data is acceptable. A different sort of difference between the technology of data capture and what is culturally acceptable appears in a recent edition of the New York Times style magazine. 
The photographers, stylists, graphic artists, and editorial team put out a publication of the highest quality; the photographers and stylists are among the most highly regarded image makers. It is somewhat surprising, perhaps, to see images such as these in that publication. Kodak has told us (along with many others) that the main subject should be in focus, the horizon should be straight, there should not be objects obscuring the subject. Yet here we have violations of those rules for photon data capture being violated in significant ways. These violations are not likely due to primitive or inadequate equipment being the only data capture tools available. Evidently (perhaps) the image makers played with the current cultural assumptions in order to grab the attention of the viewers, possibly expecting that viewers would wonder "How can this be in this publication?" and engendering closer examination.
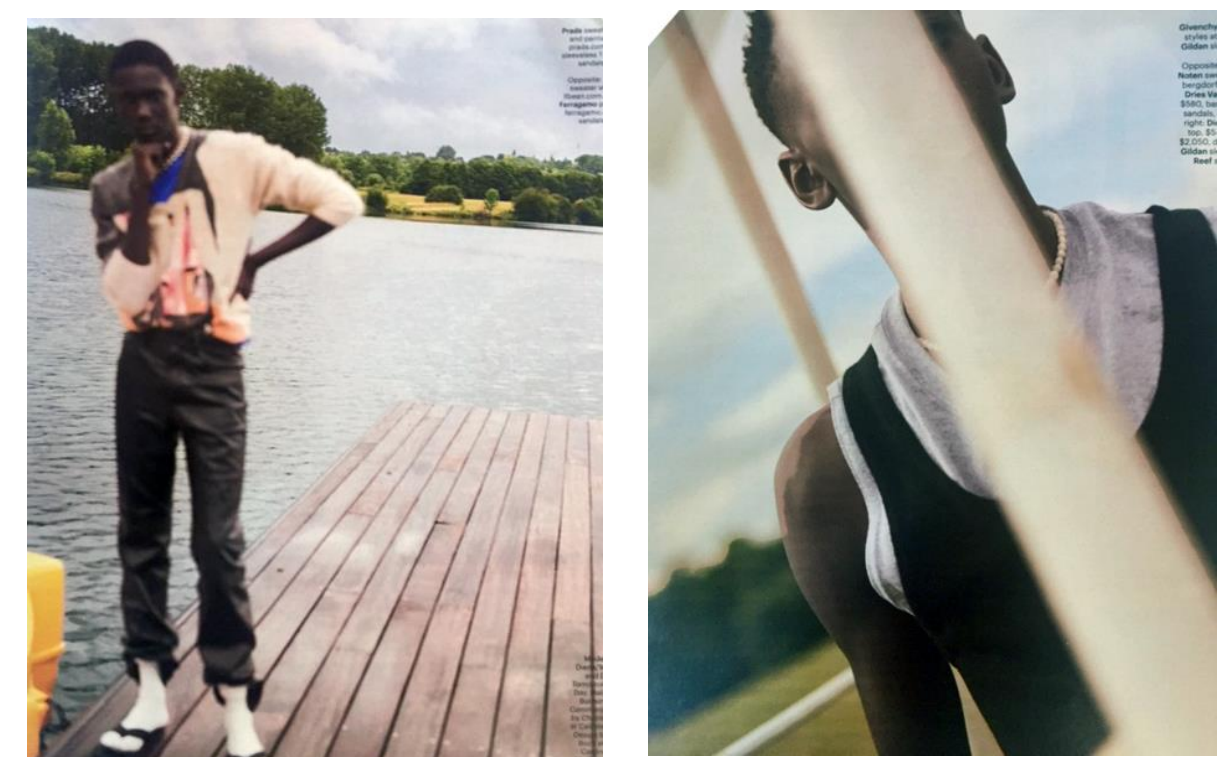

Images13,14: photographs from New York Times Style Magazine 2017

These few examples give a few examples of how photographs made under one set of authoring assumptions about recording equipment and what would be acceptable to an assumed set of viewers might not be in sync with some set of viewers in some different environment of technical capabilities and assumptions, together different assumptions about which photons are legally or culturally available for view. 
We argue that the possibility of direct presentation of photon data - data that would have been available whether recorded or not - presentation without translation into some other coding system, limits the possibility of a photograph being "bad" in and of itself. A photographer working in one place and time can make some assumptions about what a local viewer would find acceptable and might be able to make a reasonable guess at what might be acceptable to viewers at some greater remove, but that becomes more and more problematic. This does not mean that there are no mechanical or cultural restraints; but it does suggest that "badness" arises from lack of synchrony in the dance between message maker and message viewer.

The arguments and assertions we make here about photographs act as foundation stones upon which to consider anew how we might go about reasoning with specificity rather than generality. That is, how we might go about reclaiming the specificity of experience modeled by Varnant and Detienne (1991) in Cunning Intelligence in Greek Culture and Society. Enabling in new ways engagement with non-deterministic models of the lived life as suggested by Dreyfus (1992); Klaver (2014); O'Connor, Copeland, Kearns, (2003).

Formal End 


\section{Duckoda: Stomping up a storm}

Straightening the horizon, cropping the image to emphasize the two foremost ducks, brightening the image to highlight the feet, and adding a caption that indicates activity might yield a "better" picture for some viewers.

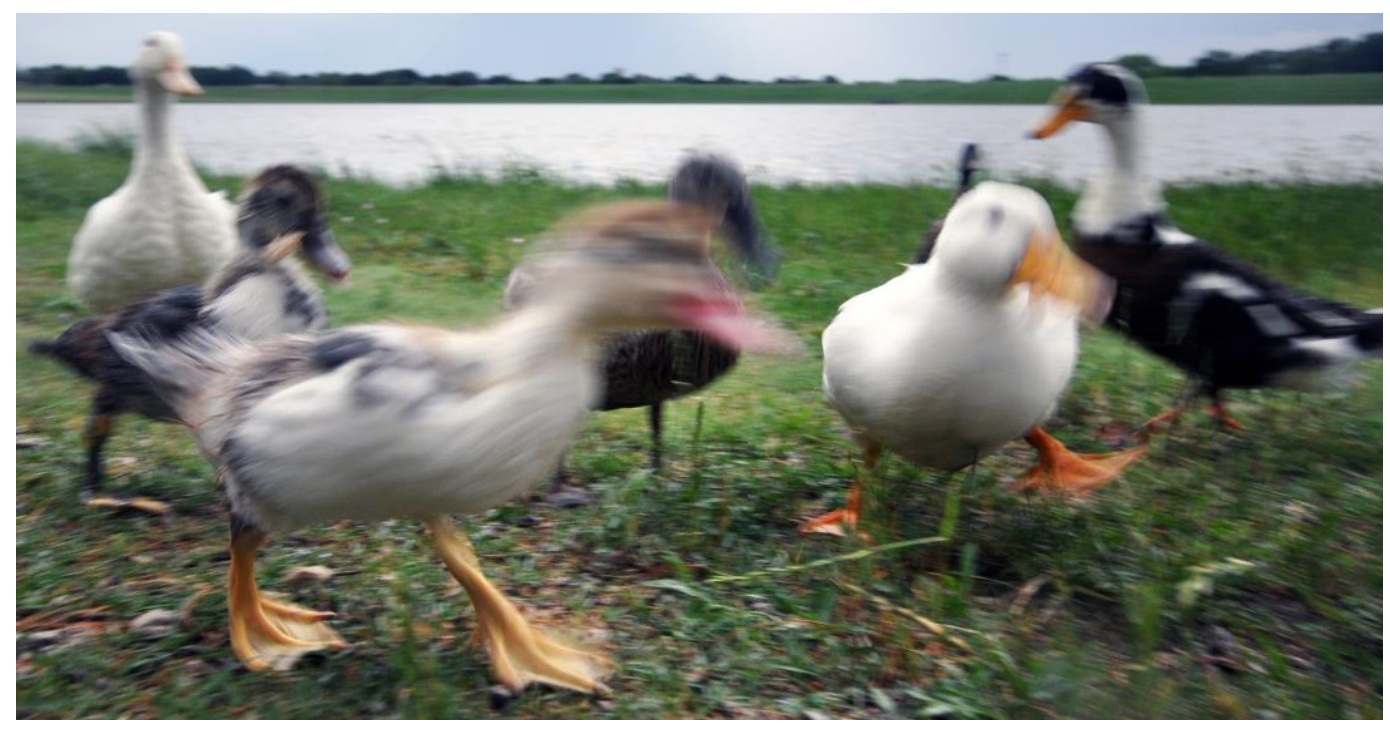




\section{References}

Note on Images

All image sources not stated were made or are the property of the authors.

Use of images that are not our own complies with the "Code of Best Practices in Fair Use for Scholarly Research in Communication" from the Center for Media and Social Impact, http://cmsimpact.org/code/code-best-practices-fair-use-scholarly-research-communication/

Ronda Rousey photograph by Peggy Sirota for ESPN “Body Issue: Bodies We Want" 2012."

http://www.espn.com/espn/photos/gallery/_/id/8136693/image/2/ronda-rousey-2012-bodyissue-bodies-want-espn-magazine

Carlos Bocanegra photograph by Richard Phibbs for ESPN "Body Issue; Bodies We Want" 2012. http://www.espn.com/espn/photos/gallery/_/id/8136693/image/3/carlos-bocanegra-2012-

body-issue-bodies-want-espn-magazine

The photographs in "State of Play" in The New York Times Style Magazine September 10, 2017 were photographed by Karim Sadli and styled by Max Permain.

Dreyfus, Hubert L.. What Computers Still Can't Do: A Critique of Artificial Reason. Cambridge : MIT Press, 1992.

Eastman Kodak Company. How to Make Good Pictures: A Book for the Everyday Photographer. Rochester, NY : Eastman Kodak, 1922.

Flusser, Vilem. Towards a Philosophy of Photography. Translated by Anthony Mathews. London : Reaktion Books, 2000.

Hayes, Robert. "Measurement of Information." Information Processing and Management, 29(1), pp.1-11, 1993.

Holmes, Oliver Wendell. "The Stereoscope and the Stereograph." The Atlantic, June 1859.

Holmes, Oliver Wendell. "A Stereoscopic Trip Across the Atlantic." The Atlantic, July 1861.

Kearns, Jodi L. and Brian C. O'Connor. "Dancing with Entropy: Form Attributes, Children, and Representation." Journal of Documentation, 60(2), pp.144-163, 2004. 
Klaver, Irene J.. "Meander(ing) Multiplicity," in Mediterranean Mosaic: Water Scarcity, Security and Democracy. Edited by Gail Holst-Warhaft, Tammo Steenhuis, and Francesca de Châtel. Atkinson Center for a Sustainable Future, Cornell University, and Global Water Partnership-Mediterranean, pp.36-46, 2014.

O'Connor, Brian C., Jud H. Copeland, Jodi L. Kearns. Hunting and Gathering on the Information Savanna: Conversations on Human Information Seeking Behavior. Lanham, MD : Scarecrow Press, 2003.

O'Connor, Brian C., Jodi L. Kearns, and Richard L. Anderson. Doing Things with Information: Beyond Indexing and Abstracting. Westport, CT : Libraries Unlimited, 2008.

O'Connor, Brain C. and Roger B. Wyatt. Photo Provocations: Thinking in, with, and about Photographs. Lanham, MD : Scarecrow Press, 2004.

O'Connor, Ethan M. and Brian C. O'Connor "Verisimilitude: Representation and Ultra-High Resolution Photographs of Realia," DOCAM 2008.

Riefenstahl, Leni. Olympia. Revised version in English. New York : St. Martin's Press, 1994.

Vernant, Jean_Pierre and Marcel Detienne. Translated by Janet Lloyd. Cunning Intelligence in Greek Culture and Society. Chicago : University of Chicago Press, 1991. 